\section{THE SOCIAL SYSTEM OF TERMITES. ${ }^{1}$}

THOUGH more than a century has elapsed since Smeathman published the first careful account of Termitidæ, but few workers have substantially increased our knowledge of the subject. The reasons for this apparent apathy lie, indeed, on the surface. With few exceptions the Termites are tropical or sub-tropical in habitat ; avoiding light, and living in vast concealed communities, their cryptic manner of life renders the task of observation extremely prolonged and arduous, while the multiplicity of forms in a single species, and the difficulties attending their preservation, have earned them little regard from the systematist.

The first marked advance towards unravelling the complexity of the Termite community was made by the great naturalist so lately lost to science, Fritz Müller. Following out Lespès' observations on the nymphs, he showed that a certain number of Termitidæ reach maturity and propagate without leaving the nest or acquiring the imaginal characteristics, and contended that the function of the swarming adults was not that of founding fresh colonies, but of furnishing royal pairs to pre-existing orphaned nests.

His conclusions were supported by observations in nature, but were not made the subject of experiment; they are to be regarded as suggestions, which, however, approach very nearly to the truth.

The subject was taken up by Prof. Grassi in order to investigate the origin of the sterile castes, and the results of seven years' labour have been put forward in a monograph which, for the first time, places the nature of the Termite society beyond the reach of speculation. Intricate as the memoir is in the presentation of facts and inferences, it cannot but leave the reader with a profound sense of the perseverance, fertility in experiment, and deductive ability which it reveals.

Species of two genera, Calotermes and Termes, were studied, and success was largely due to the fact that it was found possible to keep small numbers of the former genus alive for long periods in corked test-tubes containing rotten wood. Careful observation thus became practicable, and by varying the number and kind of individuals introduced, their development and inter-relations could be studied.

Grassi's work on Calotermes shows that the eggs are of one kind and the newly-hatched larvæ undifferentiated, the caste distinctions arising after birth, and depending on the development of the genitalia. If this proceeds normally, the larva ultimately becomes a winged imago ; if it is arrested at any period before the completion of the nymph-stage, the larva becomes a soldier; and finally, if it is precociously stimulated, a neoteinic form is produced, one, that is, which reaches sexual maturity without ever acquiring the imaginal characters. The insect remains plastic until the atrophic change of the genitalia has been set up ; thus, a soldier-larva or soldier cannot be modified, but a nymph can be converted into a soldier possessing wing-buds (a "nymph-soldier"). These buds may be subsequently reabsorbed, so that a retrogression actually takes place. The colony is headed normally by a single king and queen derived from the perfect insects; should either or both be missing, their place is supplied by neoteinic "substitute" forms, which are then always produced if the society contains examples capable of undergoing this modification. An orphaned colony may be made to produce a much larger number of substitutes if subdivided into small societies than if kept together, and the same is true of the soldiers. This and similar observations go clearly to show that the modification of these individuals is no way predestined.

1 "The Constitution and Development of the Society of Termites, \&c." By Prof. B. Grassi and Dr. A. Sandias. English translation in the Quarterly Journal of Microscopical Science, vols. 39 and 40 ; with five plates.

NO. 1457 , VOL. 56]
The insects must possess the faculty for estimating a numerical ratio, and if the number of soldiers or royal substitutes is in excess of their needs, the supernumeraries are killed and eaten!

The colony of Termes is more complex and more difficult to study: it is similar in character except that it contains two sterile castes, soldiers and workers, and two kinds of neoteinic forms ; one, the "complementary royal forms" are constantly present in large numbers as the ordinary reproductive members; the other, the "substitute forms," are developed on an emergency to supply their loss. In Sicily, according to Grassi, the winged imagos are entirely lost after swarming, and never give rise to fresh societies; but there is evidence that this remarkable example of natural wastefulness is not constantly exhibited in France. According to Marlatt, the closely-allied Termes flavipes of North America is known to reproduce by means of complementary forms alone.

Grassi holds that the caste-modifications are caused by variation in nutriment, and records a series of minute observations on the rather repulsive feeding-habits of these insects, made chiefly by his coadjutor Dr. Sandias. The staple food is wood, passed and repassed through the alimentary canal of several individuals; the society tolerates no waste, and everything of nutritive value, cast skins and dead bodies alike, is greedily devoured.

Newly-born larvæ and forms destined. for sexual maturity are fed upon the saliva of their comrades, the largest amount being given to those which are becoming neoteinic; within forty-eight hours after its administration they become altered, acquiring ocular pigmentation and a translucent white appearance.

It is therefore contended that sexual development is directly stimulated by the saliva taken as food; but a disturbing factor has had to be eliminated. The alimentary canal of most Termites teems with protozoa, which bring about the dilatation of a cæcal ampulla so as to fill the greater part of the abdomen. These protozoa disappear under the influence of a salivary diet, and the question has arisen whether the resulting diminution in size of the ampulla may cause the gonads to ripen. Grassi answers this in the negative. All Termites lose their parasitic protozoa at the time of moulting, and by taking advantage of this circumstance he has been able to keep colonies alive for a month or more entirely free from protozoa. A few examples only in these colonies became neoteinic ; and it is therefore clear that the saliva is one, if not the only, necessary factor in bringing about sexual maturity.

No light has been thrown on the causes which, in Termes, lead to the differentiation of the soldier from the worker; but it may be reasonably inferred that they are also due to differences in nutrition.

As already indicated, the results of this research are directly opposed to the hypothesis that special ova or special sets of "determinants" exist for the various castes in Termitidæ. It is not necessary here to dwell upon this point, which, it may be recollected, has been dealt with conclusively by Mr. Herbert Spencer in his controversy with Prof. Weismann (Contemporary Revieze, October 1894).

The means by which the special characters of the sterile rastes are inherited is a matter which has caused Prof. Grassi some trouble. In the original memoir he appears scarcely to have made up his mind on the point ; but in a footnote appended to the English translation he puts forward the supposition previously advanced by him in the case of bees, that it is to be interpreted by the exceptional occurrence of soldiers and workers capable of oviposition. This view is supported by the discovery of a "nymph-soldier" with well-developed ovarian tubes. Much more evidence is still required as to the occasional existence of fertile soldiers and workers, especially in 
species, if such exist, in which the caste distinctions are still incipient. If it can be shown that the evolution of caste characters is in any way anterior to the loss of fertility, the difficulties of interpretation will disappear; at present the evidence points to the fact that owing to qualitative changes in nutrition, rather than simple malnutrition, an atrophy of the sexual organs is set up which is correlated with a hypertrophic modification of other structures, by a deflection, so to speak, of the nutritive stimulus.

Many neoteinic forms show no trace of wings. If the termite colony were headed by such forms only, the phenomenon, as Grassi points out, would occasion no surprise, but all valid evidence would be wanting that the species had ever possessed wings. This leads to the admission on his part that there is no proof that all existing wingless insects may not be descended from winged ancestors, and in the absence of such a proof he is led to reject Brauer's division of Insecta into Apterygogenea and Pterygogenea.

Space forbids any reference to the full account of the social life, habits and instincts of the species which Prof. Grassi has studied. Their intelligence, though remarkable, is far inferior to that of ants, and may be profitably contrasted therewith. Whilst referring to this subject, it may be worth while to call the attention of those interested in animal psychology to two lately-published pamphlets on the subject, particularly that on the psychology of ants, ${ }^{1}$ by Father Wasmann, a most careful observer and thorough student of animal intelligence.

One practical result of Grassi's work requires mention. An isolated group of ten or a dozen Termites, containing any forms which have not begun to undergo the atrophic changes induced in the sterile castes, is capable of converting such forms into reproductive individuals; and the little society, thus started, possesses the power of multiplying into a large colony.

It is therefore hopeless to attempt the extermination of Termites merely by the destruction of the kings and queens.

W. F. H. BLANDFORD

\section{PERIODICAL COMETS.}

$\mathrm{T}$ $\mathrm{EE}$ number of comets of short period which are expected to return to perihelion during the next two years is remarkable. In 1898 the following comets are due :-Pons-Winnecke (April), Encke (May), Swift, 1889 VI. (June), Wolf (June), Tempel, I867 II. (September); in I899, Denning, I88I V. (January), Tempel, I 866 I. (March), Barnard, I892 V. (April), Tuttle, I858, I. (May), Holmes (May), and Tempel 1873 II. (July). In addition to these, 1898 may possibly witness a return of Biela's comet, last seen in 1852 , and of Coggia's, 1873 VI. ; but these are doubtful, and the prospect of reobserving them appears to be very limited. Thus there are thirteen known comets which may present themselves for detection, but several of them will be enabled to elude observation in consequence of their unfavourable position, and in one or two cases the objects may escape owing to the uncertainty now existing as to the exact periodic times.

Apart from the large number of interesting comets which are likely to be visible, several fine meteoric showers will probably occur, for the Leonids are due in considerable abundance on November I4, I898, 1899 and 1900 , while the Andromedes ought to reappear on November 23,1898 . Both for the cometary and meteoric observer we are, therefore, entering upon a period very prolific in important phenomena.

During the first quarter of the present century the number of cometary discoveries averaged about one per

1 " Instinct und Intelligenz im Thierreich," and "Vergleichende Studien über das Seelenleben der Ameisen und der höhern Thiere," by Erich Was. mann, S.J. (Freiburg, 1897).

NO. 1457, VOL. 56] annum. The present average is about five, including periodical comets, which represent no small proportion of the whole. The rapid increase, during the last twenty years, in the number of comets of short period is very striking, and proves not only that these bodies are exceedingly plentiful, but also that the field of discovery is not nearly exhausted. They belong to the Jovian family, with periods ranging from five to nine years. Encke's comet furnishes rather an exceptional case, the period being only 3.3 years, and considerably shorter than that of any other known.

Perhaps it may be interesting to make a brief seriatim reference to the expected comets of the next two years :--

Pons-Winnecke.-This comet, due in April I898, was well observed at its last return to perihelion in June I892. The ensuing return will not be so favourable, as the comet will be much more distant from the earth, and visible only in the morning sky. This return will be much the same as in 1875 , four periods of the comet being equal to twenty-three years; thus perihelion occurred on June 30 , both in 1869 and 1892 .

Encke.-Returns in May I898. The comet will not be so well placed, owing to its southern position, as at its last return, when it was quite conspicuous in December I894 and January I895. Observations may be made satisfactorily from the southern hemisphere after the perihelion passage, as in 1832 and 1865 , when the comet was discovered in June. At intervals of thirty-three years ( $=10$ revolutions of the comet) it comes to perihelion at nearly same times as before, and its apparent path in the heavens is repeated.

Swift, I889 VI.-Considerable uncertainty is attached to the orbit of this coniet. Hind deduced a period of 8.534 years, which would bring the comet back at midsummer 1898 ; but Coniel has more recently determined the period as 8.92 years, with an uncertainty of $0^{\circ} 9$ year. If this object is redetected, it will probably be picked up accidentally by some one engaged in comet-seeking. The most favourable returns are those when it reaches perihelion in October or November.

Wolf.-This comet, which will reach its perihelion in June 1898 , was favourably observed in I 884 and I891 ; but in 1898 the conditions are not nearly so good. The following ephemeris for the next return is by A. Berberick (Ast. Journal, 253).

\begin{tabular}{|c|c|c|c|c|c|c|c|}
\hline $\begin{array}{l}\text { Date. } \\
98 . \text { - June }\end{array}$ & 3 & $\ldots$ & $\begin{array}{l}\text { R.A. } \\
\text { h. m. } \\
\text { I } 42 \cdot 3\end{array}$ & & $\begin{array}{c}\text { Dec. } \\
+ \text { I } 8^{\circ} \text { I } 8\end{array}$ & & $\begin{array}{c}\text { Light. } \\
I^{\prime} 7\end{array}$ \\
\hline July & 5 & $\ldots$ & $\begin{array}{ll}3 & 18 \cdot 3\end{array}$ & $\cdots$ & $\begin{array}{r}+1943 \\
\end{array}$ & $\cdots$ & $2 \cdot \mathrm{I}$ \\
\hline Aug. & 6 & $\ldots$ & $449 \cdot 3$ & $\ldots$ & $+\mathrm{I} 65 \mathrm{I}$ & $\ldots$ & $2 \cdot 3$ \\
\hline Sept. & 7 & $\ldots$ & $4 \% 9$ & $\ldots$ & $+\mathrm{IO} 2$ & $\ldots$ & $2 \cdot 4$ \\
\hline Oct. & 9 & $\ldots$ & $656 \cdot 9$ & $\ldots$ & $+03^{8}$ & $\ldots$ & $2 \cdot 4$ \\
\hline Nov. & IO & $\ldots$ & 7 I7 9 & $\ldots$ & $-92 \mathrm{I}$ & $\cdots$ & $2 \cdot 4$ \\
\hline Dec. & 12 & $\ldots$ & $7 \quad 4^{\prime}$ & $\ldots$ & -1620 & $\ldots$ & $2 \cdot I$ \\
\hline -Jan. & 13 & tnes & $634 \mathrm{I}$ & I. & $\begin{array}{l}-163^{3 \mathrm{I}} \\
=\mathrm{I} .)^{2}\end{array}$ & $\ldots$ & $I^{*} 4$ \\
\hline
\end{tabular}

Dr. Berberick remarks that later returns of the comet will be unfavourable. Seven of its revolutions are equal to three of Jupiter, and a second approach of these bodies will occur in 1922-23, depriving us perhaps of the sight of the comet for a long time, if not for ever.

Tempel, 1867 II.-Comes to perihelion in September I 898. This comet was re-observed in 1873 and 1879 , but has not been seen since, though it has twice returned to perihelion in the meantime. The conditions in 1898 are not very good. The periodic time was about six years in I 867,1873 and 1879; but perturbations by Jupiter have considerably lengthened the period according to Gautier. It is most important that the comet should be redetected if possible.

Denning, I88 I V.-Returns to perihelion in January I 899 , but under circumstances not nearly so favourable as in I88I. In January and February its distance from the earth will be about 100 millions of miles, and about 